D.O.I.: $10.3895 / \mathrm{S} 1808-04482010000300002$

\title{
FRAGILIDADES E PERSPECTIVAS DO SISTEMA DE PROTEÇÃO À PROPRIEDADE INTELECTUAL NO BRASIL
}

\section{FRAGILITY AND PERSPECTIVES OF SYSTEM TO PROTECT INTELLECTUAL PROPERTY IN BRAZIL}

\author{
José Matias-Pereira $^{1}$ \\ ${ }^{1}$ Universidade de Brasília - UnB - Brasil \\ matias@unb.br
}

\begin{abstract}
Resumo
O objetivo deste artigo é analisar as fragilidades e perspectivas da gestão do sistema de proteção à propriedade intelectual no Brasil, em particular o registro de patentes e marcas. A análise teve como base o arcabouço institucional do país na área objeto do estudo: Lei de Propriedade Industrial, de 1996, as diretrizes de Política Industrial, Tecnológica e de Comércio Exterior, de 2004, a Lei de Inovação Tecnológica, de 2005, a Lei do Bem, de 2005, a Política de Desenvolvimento Produtivo, de 2008, o Plano de Ação de Ciência, Tecnologia e Inovação para o Desenvolvimento Nacional - 2007-2010. O exame dos aperfeiçoamentos que foram introduzidos no arcabouço institucional do Brasil nos últimos anos, e as melhorias que provocaram na gestão das políticas públicas de proteção à propriedade intelectual evidenciou que ainda existem sérias dificuldades na implantação e gestão dessas políticas, em particular no segmento de registro de marcas e patentes.
\end{abstract}

Palavras-chave: política industrial e tecnológica; propriedade intelectual; marcas e patentes; desenvolvimento econômico; Brasil.

\section{Introdução}

O emprego intensivo da ciência e tecnologia e inovação numa economia, conforme mostra a literatura, permitem a elevação da capacidade de competir, criando empreendimentos, empresas, empregos e marcas comerciais. Essa estratégia, por sua vez, tende a aumentar a interação entre política industrial e tecnológica e propriedade intelectual. Entendemos, ainda, que a gestão das políticas públicas de proteção à propriedade intelectual, como instrumento para apoiar o crescimento econômico do país apresenta deficiências. Nesse sentido, argumentamos que as fragilidades e as inconsistências da gestão das políticas na área de proteção à propriedade intelectual vêm prejudicando a competitividade das empresas brasileiras, em especial na área de patenteamento (BRASIL/MCT, 2007).

Os relatórios e discurso governamental sustentam que nos últimos cinco anos a área de C,T\&I passou a ser uma questão de Estado; o foco na Política de C,T\&I foi orientado para os eixos 
estratégicos; foram definidos novos marcos regulatórios; criados novos instrumentos e formatos de financiamento e aperfeiçoamento da gestão dos fundos setoriais; bem como um aumento dos recursos federais para C,T\&I. Em que pesem esses avanços, entendemos que os resultados alcançados pelo Brasil, após oito anos de vigência dos fundos setoriais, quatro anos de vigência da Lei de Inovação Tecnológica e dois anos e meio da Lei do Bem (Lei n ${ }^{\circ}$. 11.196/2005 / Decreto ${ }^{\circ}$. 5.798/2006), no que se refere aos resultados de registro de patentes brasileiras é bastante inquietante.

Sabemos que existem diversas maneiras de reduzir os possíveis custos da extensão do nível de abrangência das patentes. Entre elas destacamos duas opções: a primeira se refere ao emprego de mecanismos de abusos do poder econômico; a segunda trata da criação de ambientes institucionais que estimulem a atividade de investimentos em pesquisa e desenvolvimento por empresas que operam nesses setores através da necessária articulação governo - iniciativa privada-universidade. Entendemos que o Brasil, a partir de um efetivo esforço para melhorar a gestão de políticas de proteção à propriedade intelectual, deveria orientar-se para a segunda opção.

Frente a esse cenário, surge a seguinte pergunta: as políticas públicas de fomento a ciência e tecnologia e inovação estão contribuindo para melhorar a gestão do sistema de proteção à propriedade intelectual no Brasil?

O objetivo principal deste artigo é analisar as fragilidades e perspectivas da gestão do sistema de proteção à propriedade intelectual no Brasil, em particular o registro de patentes. Usamos como referências o estudo de Guimarães, "Políticas de Inovação: Financiamento e Incentivos", de 2006; a Lei de Propriedade Industrial, Lei nº. 9.279/1996 (denominada Código da Propriedade Industrial); as diretrizes de Política Industrial, Tecnológica e de Comércio Exterior, de 2004; a Lei de Inovação Tecnológica, de 2005; a Lei do Bem (Lei no . 11.196/2005 / Decreto $n^{\text {o }}$. 5.798/2006) ${ }^{1}$, o Plano de Ação de Ciência, Tecnologia e Inovação para o Desenvolvimento Nacional - 2007-2010; e, a Política de Desenvolvimento Produtivo, de 2008.

Registre-se que das vinte e uma prioridades definidas no Plano de Ciência, Tecnologia e Inovação para o Desenvolvimento Nacional - Plano de Ação 2007-2010 - estão diretamente relacionadas com os quatro eixos estratégicos que norteiam a atual Política Nacional de C,T\&I: expandir, integrar, modernizar e consolidar o Sistema Nacional de Ciência e Tecnologia e Inovação (SNCTI), atuando em articulação com os governos estaduais para ampliar a base científica e tecnológica nacional; atuar de maneira decisiva para acelerar o desenvolvimento de um ambiente

\footnotetext{
1 Lei do Bem (Lei no. 11.196/2005 / Decreto nº 5.798/2006), A Lei do Bem institui o Regime Especial de Tributação para a Plataforma de Exportação de Serviços de Tecnologia da Informação (Repes), o Regime Especial de Aquisição de Bens de Capital para Empresas Exportadoras (Recap) e o Programa de Inclusão Digital. A citada Lei do Bem, além de dispor sobre incentivos fiscais para a inovação tecnológica, cuida ainda de outras questões tributárias, instituindo até mesmo outros regimes especiais de tributação. No tocante aos incentivos à inovação, a Lei nº. 11.196/05 dá cumprimento à determinação da Lei no 10.973, de dezembro de 2004.
} 
favorável à inovação nas empresas, fortalecendo a Política Industrial, Tecnológica e de Comércio Exterior (PITCE); fortalecer as atividades de pesquisa e inovação em áreas estratégicas para a soberania do País, em especial energia, aeroespacial, segurança pública, defesa nacional e Amazônia; e promover a popularização e o ensino de ciências, a universalização do acesso aos bens gerados pela ciência, e a difusão de tecnologias para a melhoria das condições de vida da população. Estão previstos no Plano a aplicação de R\$ 41 bilhões para o período de 2007-2010. O Plano tem como propósito expressar a configuração da nova Política Nacional de Ciência, Tecnologia e Inovação, orientado para estimular o desenvolvimento econômico e social do país (MCT, 2008).

Trata-se de um artigo teórico-empírico e exploratório. Em termos metodológicos a pesquisa é qualitativa e bibliográfica. Registre-se que, diante da amplitude e complexidade do tema, não temos a pretensão de esgotar o assunto objeto deste estudo.

\section{Dinâmica do Crescimento e Processo de Industrialização}

A relevância do progresso tecnológico tem sido retratada teórica e empiricamente há várias décadas, com destaque para a contribuição de Joseph Schumpeter (1982), que nas primeiras décadas do século XX, demonstrou a importância do processo de inovação para o crescimento do produto. $\mathrm{Na}$ década de cinqüenta, Robert Solow (1988), criou as bases para a construção da teoria do crescimento econômico. No primeiro estudo, desenvolveu um modelo teórico que sustenta o fato de que, sem progresso tecnológico não há crescimento sustentado do produto per capita (Solow, 1956). Para o país alcançar o progresso duradouro é necessário que se permita que a economia possa agregar algo à produção, sem necessariamente acrescentar mais mão-de-obra e capital. Solow denominou essa fonte de riqueza de "progresso tecnológico". No segundo artigo, buscou demonstrar, num exercício empírico, que o progresso tecnológico foi o maior responsável pelo crescimento da economia norte-americana (Solow, 1957). Registre-se, entretanto, que aquele teórico não conseguiu explicar o que levava ao progresso tecnológico. Coube a Paul Romer, na segunda metade da década de oitenta, propor nova abordagem na teoria econômica sobre o desenvolvimento ("Novas Teorias de Crescimento", 1986, 1987, 1990 e 1993). Nesses estudos seminais sobre a teoria do crescimento econômico, incorporou a inovação tecnológica, ou seja, a produção de idéias, como o principal impulsionador do crescimento. Por sua vez Warsh (2006) sustenta que Romer ampliou o campo de percepção da ciência econômica para capturar um mundo - a economia do conhecimento - expressa até então de forma muito vaga.

Para a compreensão de fenômenos associados à mudança econômica nos apoiamos na teoria evolucionária (NELSON e WINTER, 1982). Para essa linha de pensamento, são as competências dos agentes econômicos que determinam seu comportamento tendo como parâmetro uma 
racionalidade que é limitada. Na perspectiva evolucionária, o capitalismo é dominado essencialmente pela mudança econômica resultante do impacto do processo de inovação (ROSENBERG, 1994). Inovação baseada no progresso técnico, o qual, segundo Dosi (1988), é fator determinante para competitividade internacional.

\subsection{Invenções e Inovações Tecnológicas e Propriedade Intelectual}

As invenções e inovações tecnológicas, ao longo da História, sempre foram vistas com certa reserva e desconfiança pela humanidade. Observa-se, entretanto, que essas resistências tendiam a desaparecer quando as pessoas começavam a perceber nas novas idéias, vantagens materiais, econômicas ou militares ${ }^{2}$. Verifica-se que prêmios e estímulos por parte dos governos, e gastos de indivíduos com pesquisas aplicadas, tornaram-se uma constante. Nos últimos sessenta anos foi sendo implementada nos países mais evoluídos, de forma cada vez mais consistente, a aplicação do conhecimento científico para fomentar o desenvolvimento tecnológico e à inovação. As atividades de P\&D seriam, então, o iniciador e o indicador fundamental da inovação.

Verifica-se, no campo da propriedade intelectual, que ocorreram mudanças significativas a partir do começo da década de oitenta. As empresas multinacionais, a partir daquela penúltima década do século XX, intensificam as suas estratégias de globalização do mercado. Isso foi responsável pelo aumento dos gastos em investimentos de pesquisa e desenvolvimento (P\&D) em setores relacionados às novas tecnologias. A internacionalização dos mercados passa a exigir tanto a liberalização dos fluxos de mercadorias, serviços e capitais, por um lado, como um nível mais elevado de harmonização nas normas que definem o ambiente institucional no âmbito da concorrência, com destaque para o sistema de propriedade industrial. Com o aumento da participação dos gastos em investimentos de pesquisa e desenvolvimento nos novos produtos as patentes passam a representar um fator importante no cálculo de taxa de rentabilidade privada do investimento. A tecnologia, dessa forma, torna-se um fator primordial na quantificação das vantagens comparativas nos mercados mundiais. Assim, a garantia obtida com a proteção ao conhecimento por meio do sistema de patenteamento passa a ter uma enorme importância na estratégia concorrencial das empresas (MATIAS-PEREIRA, 2004; MATIAS-PEREIRA et al., 2006; MATIAS-PEREIRA, 2009).

$\mathrm{Na}$ estruturação dos padrões de transformação da economia a mudança técnica é um fator essencial. Verifica-se, entretanto, que a tecnologia não é um bem livre, visto que a sua apropriação decorre do nível acumulado de conhecimento, dos processos passados de aprendizado, das

\footnotetext{
${ }^{2}$ A Classificação Internacional de Patentes teve suas primeiras discussões no início dos anos 1920. O texto da primeira edição da CIP foi estabelecido de acordo com a convenção européia para a classificação internacional de patentes em 1954. A primeira edição é datada de 1969. A classificação é periodicamente revisada a partir de reuniões de peritos dos Países Membros da Organização Mundial da Propriedade Intelectual. Essa classificação pode ser acessada nos sites do INPI e da OMPI.
} 
experiências das empresas e do próprio meio institucional que pode ou não funcionar como um elemento redutor da incerteza das decisões de investimento em novos processos ou produtos (FREEMAN, 1988). Deve-se considerar, ainda, que os distintos segmentos industriais se diferenciam em termos de sua capacidade de promoverem difusão tecnológica. Assim, o avanço do progresso tecnológico repercute positivamente no processo de crescimento econômico.

Observa-se que o debate da função do sistema de patentes não é uma coisa nova (PENROSE, 1951). O que fica evidente nesse debate, na atualidade, é a elevada prioridade conferida ao sistema ao sistema de proteção aos direitos de propriedade intelectual por todos os países, em especial ao sistema de patenteamento, tanto em nível interno como em nível internacional.

A tecnologia é um fator preponderante na determinação das vantagens comparativas dos países no comércio mundial. O que não é uma proposição nova. A teoria do hiato tecnológico (POSNER, 1961) e a do ciclo do produto (VERNON, 1966) já apontavam a forma de difusão do progresso tecnológico como um dos fatores subjacentes ao padrão e à dinâmica do comércio internacional. A diferença é que na nova etapa tecnológica o principal fator de produção é o conhecimento ou a informação (BIFANI, 1989). Neste sentido, cresce o valor econômico do conteúdo de conhecimento embutido em novos processos ou produtos. E, logo, aumenta também a relevância da propriedade industrial sob dois aspectos. Primeiro porque essa permite a proteção privada do novo conhecimento. E segundo, porque confere a possibilidade de extrair rendas através da propriedade dos novos conhecimentos.

Deve-se ressaltar que, nem toda patente corresponde a uma invenção. Na verdade uma grande parcela de patentes decorre de pequenas inovações realizadas em equipamentos e processos existentes (KIM, 1997).

\subsection{Indicadores de Ciência, Tecnologia e Inovação do Brasil}

Torna-se possível argumentar que o Brasil encontra-se numa posição intermediária entre os países que buscam colocar a produção de conhecimento no centro do desenvolvimento econômico e social. Os recursos aplicados em ciência, pesquisa e fomento tecnológico representam 1,0\% do PIB, média semelhante à de nações como a Espanha (0,94\%), mas muito distante das maiores economias, como os Estados Unidos (2,7\%) e Japão (3\%), ou de tigres asiáticos, como a Coréia do Sul (2,5\%). Nestes países, por outro lado, a iniciativa privada, em especial a indústria, responde por $63 \%$ dos investimentos em pesquisa e tecnologia, enquanto nas nações intermediárias no setor o governo assume cerca de $60 \%$ dessas inversões. Dos investimentos aplicados em P\&D no Brasil (OCDE, 2000), o setor público foi responsável por 63\%, enquanto os restantes $37 \%$ ficaram por conta do setor privado. Os investimentos feitos em P\&D naquele ano chegaram a 1,07\% do PIB 
brasileiro. A taxa histórica dos dispêndios governamentais em P\&D no Brasil é de $0,8 \%$ do PIB (MCT, 2004).

\section{Propriedade Intelectual e Registro de Patentes no Mundo}

Observa-se que a propriedade intelectual alcançou a sua atual importância em decorrência das inúmeras e sistemáticas evoluções em seus conceitos. Entre os fatores que têm atribuído maior valor à propriedade intelectual destacam-se: a sua visibilidade política, devido à grande importância econômica para os países; e a constatação de que os bens imateriais superaram a tradicional estimativa concedida aos bens materiais e imóveis. Verifica-se, dessa forma, que os bens intangíveis de uma indústria, em geral, são mais valiosos que o conjunto de seus ativos materiais. Essa realidade foi a responsável pela acelerada evolução do sistema de registro de patentes no mundo, conforme se pode verificar na discussão a seguir.

A Organização Mundial de Propriedade Industrial - OMPI define a patente como um documento expedido por um órgão governamental, que descreve a invenção e cria uma situação legal, na qual a invenção patenteada pode normalmente ser explorada (fabricada, importada, vendida e usada) com autorização do titular. Nesse sentido, o requisito de patenteabilidade se apresenta como a principal característica do documento de patente. Isso significa que pode ser patenteável a invenção que atenda aos requisitos de novidade, ou seja, aquilo que não tenha sido divulgada antes. Parte-se do entendimento que ela seja inédita, portanto que não tenha existido ainda, que possua atividade inventiva, e aplicação industrial, passível, portanto, de ser comercializada. Uma invenção pode ser considerada nova quando não está inserida no estado da técnica, e este é constituído por todo o registro de acesso público antes da data de depósito do pedido de patente, por descrição escrita ou oral, por uso ou qualquer outro meio, no país de origem ou no exterior.

\subsection{Ranking de Registro de Patentes do USPTO e do PCT/WIPO}

Observa-se que a capacidade de patenteamento dos países, na atualidade, tem uma forte correlação com o seu nível de desenvolvimento. Em que pese os dados divulgados pelo escritório norte-americano de patentes - United States Patent and Trademark Office (USPTO, 2005), no período de 1980-2004 mostrarem que ocorreu uma queda no crescimento do número de patentes concedidas nos países do G7 (EUA, Inglaterra, França, Alemanha, Itália, Canadá e Japão) a diferença em termos de patenteamento quando comparados ao resto mundo ainda é muito grande. Em 2007 foram feitos 214.807 pedidos estrangeiros de patentes depositados no Escritório de Marcas e Patentes do Departamento de Comércio dos Estados Unidos (USPTO, 2007). 
Registre-se que os países em desenvolvimento estão em ascensão nessas estatísticas de patenteamento do USPTO (2005). Nesses dados podemos verificar que países emergentes, como por exemplo, Taiwan e Coréia do Sul, em 2004, que na década de 80 não tinham nenhuma expressão, apareciam como grandes patenteadores mundiais, ocupando o $4^{\circ}$ e $5^{\circ}$ lugares no ranking da USPTO. No período de 2005-2007 o Brasil teve 288 patentes concedidas no USPTO (2007) ${ }^{3}$, contra 359 para a Malásia, 1410 para a Índia e 2775 para a China. Esse baixo desempenho do Brasil em termos de patenteamento revela-se bastante preocupante, considerando o tamanho e a complexidade da economia brasileira ${ }^{4}$.

O ranking de registro de patentes do Patent Cooperation Treaty (PCT), acordo ligado a World Intellectual Property Organization (WIPO), que possibilita registro de patentes em 123 diferentes países também é aceito como um importante indicador do desempenho na área de inovação tecnológica de um país. Nesse ranking em 2005 (WIPO/PCT, 2007), os Estados Unidos ocupava o primeiro lugar, com 45.452 pedidos de patentes (33,8\% do total), seguidos por Japão (24.800 pedidos, ou $18,4 \%$ do total) e Alemanha (15.981 pedidos, representando $11,9 \%$ do total). Entre os países emergentes a Coréia do Sul ocupava em 2005 a primeira posição, com 4.422 pedidos de patentes. O Brasil aparece no ranking com 275 pedidos de patentes (na sexta posição entre os emergentes), atrás da China (2.501), Índia (675), Cingapura (441) e África do Sul (360), e à frente do México (140).

Essa posição desconfortável do Brasil nos rankings do USPTO e do WIPO/PCT tem sido objeto de diversos estudos no sentido de compreender por que o Brasil possui um nível de desempenho tão medíocre em pedidos de registro de patentes no mundo. Uma das explicações para o baixo desempenho do Brasil nos principais rankings de pedidos de registro de patentes no mundo (USPTO e WIPO/PCT) estaria relacionada á baixa proporção de pesquisadores que estão atuando nas empresas. Nos países desenvolvidos, até $80 \%$ dos pesquisadores e seus estudos estão localizados nas empresas, enquanto os restantes $20 \%$ se encontram na academia. No Brasil esta situação é inversa.

Observa-se, com base nos referenciais internacionais, que o Brasil possui uma base de pesquisa acadêmica competitiva (MCT, 2004). A base de pesquisa empresarial, entretanto, é bastante frágil. Dessa forma, o grande obstáculo a ser superado é a implementação adequada das políticas públicas orientadas para gerar estímulos para que as empresas do Brasil possam empregar cientistas e engenheiros para fazer desenvolvimento tecnológico nas empresas.

\footnotetext{
${ }^{3}$ O registro de patentes brasileiras no USPTO caiu 13\% no triênio 2005/2007 em comparação com o triênio 2002/2004, período no qual o Brasil obteve o registro de 332 patentes.

${ }_{4}$ O Brasil encerrou o ano de 2008 com um saldo de apenas 90 patentes concedidas nos EUA, contra 1.121 para a China, 545 para a Índia, e 158 para a Malásia. Isso explica a queda do país para o $29^{\circ}$ lugar na lista geral do USPTO. Deve-se destacar, também, que o depósito de patentes dentro do Brasil é igualmente reduzido. Em 2007, foram solicitadas, por todos os países, 24.107 patentes e desenhos industriais, das quais foram concedidas apenas 1.855 (INPI. 2008).
} 


\section{Políticas Públicas de Proteção à Propriedade Intelectual}

Na medida em que as políticas e gestão de ciência e tecnologia estão a cargo do setor público é perceptível que a avaliação da qualidade das instituições voltadas à gestão e à formulação de política científica e tecnológica encontra resistências ${ }^{5}$. Observa-se que o Brasil ainda não conseguiu desenvolver um sistema de administração pública de gestão de propriedade intelectual compatível com as exigências das demandas num mundo globalizado.

A questão da proteção à propriedade intelectual se apresenta como uma área sensível e importante para apoiar o processo de desenvolvimento do país (OCDE, 2003). É nesse setor que estão ocorrendo, na atualidade, os maiores enfrentamentos no mundo, visto tratar-se do controle de dois fatores estratégicos para qualquer país: o domínio da tecnologia e da informação proprietária. São os denominados ativos intangíveis - apropriados sob a forma de títulos -, responsáveis pela geração de royalties, por meio da exploração de marcas e patentes, e copyright, pela reprodução de obras artísticas e literárias (MATIAS-PEREIRA; KRUGLIANSKAS, 2004).

É oportuno ressaltar que, a propriedade intelectual compreende todas as regras relativas à proteção dos direitos de propriedade industrial, os direitos de autor e do savoir-faire. Nesse sentido, a patente de invenção além de estimular a atividade inventiva e facilitar o intercâmbio de conhecimento, ela também desempenha um papel importante na circulação de informações científicas e técnicas e contribui assim para o enriquecimento do patrimônio tecnológico da sociedade (CHAVANNE; BURST, 1993).

A propriedade industrial pode ser aceita como um instrumento legal que estimula uma maior competitividade entre indivíduos ou empresas e promove a concorrência e o avanço tecnológico. Assim, a propriedade industrial é importante para o equilíbrio das relações entre indústrias, na medida em que define mecanismos de colaboração entre estas e com universidades, institutos de pesquisas e outras entidades congêneres. Considerando que o desenvolvimento de novos produtos e processos, em sua maioria, necessita de elevados investimentos, a proteção por meio da propriedade industrial passou a ter cada vez mais importância no cenário internacional, visto que se tornou um fator crítico de vantagem competitiva para o país.

A patente, por sua vez, é um privilégio legal concedido pelo Estado aos inventores e a outras pessoas detentoras dos direitos de exploração de um produto, de um novo processo de fabricação ou de um aperfeiçoamento de produto ou processo existente. A carta-patente é uma instituição econômica e jurídica que: define a propriedade tecnológica; garante o mercado para seu titular, por prazo determinado; incentiva e obriga a sociedade em geral a uma contínua renovação tecnológica.

\footnotetext{
${ }^{5}$ Observa-se que a ciência, a tecnologia e a inovação no Brasil ainda não são tratadas como questões de Estado, que devem ultrapassar os governos e devem ser tratadas como compromissos que se transferem de um período governamental para outro (MATIAS-PEREIRA, 2009).
} 


\subsection{Papel do Instituto Nacional da Propriedade Industrial}

Observa-se que o processo de globalização está afetando duramente o sistema de patentes na maioria dos países no mundo. Essa crise instalada no sistema de patentes mundial também está afetando o Brasil, nos aspectos qualitativos e quantitativos. Nos aspectos qualitativos verifica-se a crescente intenção de patentear descobertas e não invenções; as interpretações distorcidas dos conceitos de utilidade e não-obviedade, etc. Quanto aos aspectos quantitativos verifica-se nas últimas duas décadas uma elevação significativa do número de pedidos de patentes depositadas; a entrada no sistema de propriedade intelectual de novas áreas de patenteabilidade, como por exemplo, biotecnologia, nanotecnologia, informática; o crescimento da complexidade dos pedidos de patente; o maior número de países em que um mesmo pedido é depositado, entre outras. Isto tem refletido sobre a qualidade dos serviços prestados pelos órgãos encarregados de registrar as patentes (ÁVILA, 2007). Demora na análise dos pedidos, elevação do custo de patenteamento, e expedição de patentes duvidosas. Esses problemas assinalados podem ser visualizados nos relatórios de desempenho do INPI, divulgados no período de 1999 a 2008 (INPI, 2008).

O Instituto Nacional da Propriedade Industrial (INPI), autarquia federal vinculada ao Ministério do Desenvolvimento, Indústria e Comércio Exterior, é o órgão responsável no Brasil por executar as normas que regulam a propriedade industrial, levando em consideração sua função social, econômica, jurídica e técnica. Dentro dessas atribuições, estão incluídas tarefas como a concessão de registros de marcas e patentes. Dessa forma, o INPI é o único órgão em nível nacional responsável pelo registro de patentes de inovações tecnológicas.

\subsection{Metas Operacionais nas Áreas de Marcas e Patentes do INPI - 2007/2009}

O INPI, em relação as suas metas de disseminação e apoio ao desenvolvimento, busca ampliar o depósito de patentes de invenções e desenhos industriais por empresas e universidades brasileiras; ampliar o uso do PCT por brasileiros; ampliar o depósito de marcas e desenhos industriais brasileiros no exterior; e, criar indicações geográficas brasileiras.

O INPI tem como meta reduzir a quantidade de pedidos de marcas e patentes não processados de forma significativa até o final de 2006. O prazo de concessão de uma marca passará a ser de um ano, em vez dos atuais cinco anos. Outra medida posta em ação é o novo site do instituto e o sistema eletrônico para pedidos de novas marcas. Além do processamento simplificado de exame, pela entrada em operação do sistema eletrônico de pedidos de novas marcas, o reforço na área de recursos humanos, com a admissão de novos examinadores as respostas do INPI devem ser mais rápidas. Verifica-se que o número de examinadores de marcas e patentes passou de 180 para 460 examinadores até dezembro de 2006. Na área de patentes, eles passaram a ser 350 (eram apenas 
105 no primeiro semestre de 2006), enquanto os examinadores de marcas, que eram cerca de 40, aumentaram para próximo de 100 (JAGUARIBE, 2006; ÁVILA, 2007).

$\mathrm{Na}$ área de marcas, visando atingir o cumprimento das suas metas operacionais, o INPI buscou examinar todos os pedidos depositados até 2005 durante o ano de 2007. A primeira manifestação ocorreu em até 18 meses a partir do depósito, para marcas depositadas a partir de julho de 2007. A primeira manifestação para as marcas depositadas a partir de janeiro de 2008 deverá ocorrer até 12 meses a partir do depósito. Na área de patentes, em termos de cumprimento das metas operacionais do INPI, verificou-se que houve um avanço rápido, porém desigual durante o ano de 2007, ou seja, mais rápido nos segmentos que primeiro foram atendidos por novos examinadores. Por sua vez, o INPI está se preparando para que a primeira manifestação ocorra em até 24 meses a partir do pedido de exame para pedidos efetuados a partir de janeiro de 2008. A primeira manifestação em 2009 deverá ocorrer em até12 meses a partir do pedido de exame (ÁVILA, 2007).

\subsection{Síntese das Principais Ações Desenvolvidas pelo INPI em 2008}

Elaboração de um plano de integração sul-americana dos serviços de propriedade industrial, que deve ser aprovado em março. São oito os países participantes do plano: Argentina, Brasil, Chile, Colômbia, Equador, Paraguai, Suriname e Uruguai. O serviço permitirá que qualquer cidadão de países sul-americanos acesse, em um único site, informações sobre todas as patentes e marcas registradas no continente. Para implementar o sistema, o BID investirá US\$ 1 milhão, a ser utilizado para a realização do levantamento de todos os sistemas que possam ser cedidos ou licenciados para serem utilizados na futura plataforma comum.

Realização da capacitação de novos examinadores de marcas e patentes, permitindo a redução do atraso no exame de novos pedidos. Além disso, foi disponibilizado o acesso eletrônico aos serviços de patentes. Nesta ação, o INPI firmou parceria para implementar o sistema eletrônico de gestão de pedidos de patentes (e-Patentes), desenvolvido pelo Escritório Europeu de Patentes (EPO).

Publicação do Alerta Tecnológico, de veiculação semestral. A publicação tem como objetivo informar acerca dos depositantes mais expressivos em determinado período, dos países onde o primeiro depósito foi solicitado (país de prioridade), das áreas tecnológicas mais solicitadas e divulgar os títulos dos pedidos de patentes publicados mundialmente em determinado período.

\subsection{Principais Ações a Serem Desenvolvidas pelo INPI em 2009}

As principais ações previstas para o INPI em 2009 são: implantar um sistema de gestão da qualidade nas Diretorias de Marcas e Patentes; avançar na redução do backlog de marcas, 
permitindo que um pedido possa ser examinado em até 12 meses contados da data de seu depósito; consolidar o Manual de Procedimentos e as Diretrizes de Exame da Diretoria de Marcas.

Agilização do exame de pedidos de patentes para que, até o final de 2010, todos os pedidos depositados até 2004 tenham pelo menos um exame efetuado, etapa prevista para a consecução da meta de exame em quatro anos a partir do depósito.

Estruturação do serviço de informação de transferência de tecnologia baseada no banco de dados de contratos (Siscon). O projeto tem como objetivo reorganizar e desenvolver os serviços de informação.

\section{Percepção dos Empresários sobre Inovação e Propriedade Intelectual: Análise dos Resultados da Pesquisa Qualitativa}

Tendo como objetivo identificar as principais características e fragilidades da gestão das políticas públicas na área de proteção à propriedade industrial, em particular sobre patenteamento, realizou-se trinta e três entrevistas qualitativas com dirigentes de empresas industriais de grande, médio e pequeno porte, todas localizadas no Estado de São Paulo. As entrevistas foram realizadas nos meses de outubro e novembro de 2008. Apesar de tratar-se de uma amostragem limitada, somente nas empresas de grande porte se observou que existe uma consciência da importância da inovação, traduzida tanto pelo patenteamento de suas invenções como pela vigilância sobre o mercado em termos de privilégios patenteados por terceiros. Registre-se que as entrevistas foram realizadas por meio da internet. A pergunta formulada foi: qual a percepção sobre a importância e o nível de prioridade dada pela sua empresa para a questão do patenteamento? Os informantes discorreram livremente sobre o assunto em pauta. $\mathrm{O}$ tratamento dos dados obedeceu aos seguintes passos: ordenação dos dados, classificação dos dados e análise final. Os resultados obtidos na pesquisa qualitativa são importantes para reforçar as nossas conclusões sobre o nível de conhecimento da indústria acerca das questões envolvendo a gestão da proteção da propriedade industrial e as dificuldades e problemas enfrentados nesta área ${ }^{6}$.

\subsection{Destaques das entrevistas qualitativas}

\footnotetext{
${ }^{6}$ Foram importantes para elevar o nível de consistência deste artigo as exposições dos empresários, especialistas e pesquisadores que participaram do $3^{\circ}$ Encontro Nacional da Indústria - ENAI 2008, realizado em Brasília, nos dias 28 e 29/10/2008. O evento teve como objetivo avaliar, no contexto da crise financeira mundial, alternativas para maior competitividade da indústria nacional, além de maior integração do setor. Web: www.cni.org.br

É importante destacar também as contribuições da IX Conferência Anpei de Inovação Tecnológica, promovida pela Associação Nacional de Pesquisa, Desenvolvimento e Engenharia das Empresas Inovadoras - ANPEI, realizada nos dias 08 a 10 de Junho de 2009, em Porto Alegre - Rio Grande do Sul. O evento focalizou o desafio atual presente às Empresas e aos profissionais que atuam na área de inovação. Web: www.anpei.org.br
} 
A propriedade industrial - área do Direito identificada como "marcas e patentes" - é aceita por unanimidade dos entrevistados como uma área importante para as atividades industriais e empresariais em geral dos mais diversos setores. Apesar de valorizada e utilizada como instrumento de estratégia concorrencial e de competitividade nos países mais desenvolvidos, afirmam os entrevistados que o sistema de propriedade industrial é subutilizado e desconhecido por substancial parcela do empresariado.

a) A falta de proteção adequada de marcas, patentes e desenhos industriais, tanto no Brasil como no exterior, é vista por todos os entrevistados como bastante prejudicial à competitividade da indústria brasileira. Isso tende a dificultar ou impedir a recuperação de investimentos em pesquisa e desenvolvimento e pode ser causa de vultosos prejuízos, perda de clientela e de oportunidades comerciais;

b) As empresas e instituições nacionais, em geral, parecem não estar adequadamente atentas para as fortes mudanças ocorridas no cenário mundial, com profundo impacto sobre o comércio, bem como o acesso às tecnologias, onde a propriedade intelectual tem sido objeto de importância crucial na competitividade. Fica evidenciado nas entrevistas que, apesar de o mercado externo ser muito visado pela indústria, não há uma preocupação acentuada com a proteção da propriedade industrial no exterior. Isso tem criado entraves para colocação de produtos brasileiros em outros mercados;

c) Todos os entrevistados sustentam a importância do Estado orientar as políticas públicas na área de propriedade industrial, principalmente no que se refere à reestruturação e fortalecimento do INPI, para que, a partir da administração eficiente do sistema público de proteção da propriedade industrial no Brasil;

d) Os entrevistados sustentam a importância da realização de estudos consistentes pelo segmento empresarial, em parceria com o INPI, com vista a disponibilizar informações sobre a matéria propriedade industrial, para subsidiar o governo e o setor produtivo;

e) As empresas, no que se refere à inovação tecnológica, necessitam rever padrões de comportamentos, como por exemplo, a adoção de decisões que buscam resultados imediatos, aversão ao risco e egoísmo colaborativo;

f) É preciso que empresas priorizem nas suas estruturas políticas ou diretrizes e suporte às ações de Propriedade Intelectual/Patentes. Para isso é preciso que as empresas adotem políticas mais agressivas, no que se refere ao uso do Sistema de Patentes como proteção legal, bem como fonte de informação tecnológica e de mercado;

g) Para uma grande parcela dos entrevistados (especialmente os professores-pesquisadores) é importante intensificar as ações para estimular as Instituições Tecnológicas, de Pesquisas e Universidades a fortalecerem os seus Núcleos de Gestão de Tecnologia/Patentes. É preciso, 
também, disseminarem a cultura da propriedade intelectual e a utilizarem indicadores de desempenho que privilegiem o desenvolvimento de novos produtos e processos e, a parceria com indústrias como forma de incrementar as inovações.

\subsection{Visão da indústria sobre a gestão de políticas de propriedade intelectual}

A percepção de inúmeros empresários e especialistas sobre a gestão de políticas de propriedade intelectual no Brasil, contidas nas conclusões do Congresso Brasileiro de Inovação na Indústria (CNI, 2005b), respaldam as constatações feitas pela pesquisa qualitativa deste artigo. A síntese do documento assinala que: "As condições de operação do INPI constituem um óbice às empresas que pretendam estabelecer uma adequada gestão da sua propriedade intelectual. O tempo médio de 9 anos para a obtenção de uma patente e de 5,5 anos para a concessão de marca é um indicativo claro das dificuldades atualmente observadas. A isso se soma também o custo do registro de patentes, que é elevado para as pequenas empresas e que requer a contratação de assessoria jurídica especializada. O INPI possui poucos funcionários e ainda opera com níveis de informatização insuficientes. Por outro lado, há a necessidade de uma maior disseminação da cultura de proteção da propriedade intelectual entre as empresas e as instituições de ensino e pesquisa, o que tem levado em muitos casos a uma proteção inadequada dos conhecimentos gerados".

\section{Conclusões}

A avaliação do desempenho da gestão do sistema de proteção à propriedade intelectual no país revelou que, entre outras deficiências, existem dificuldades na administração dessas políticas, em particular no segmento de registro de patentes e marcas. Constata-se, assim, que políticas públicas orientadas para a área de propriedade intelectual não estão cumprindo adequadamente o seu papel, em termos institucionais e de geração de estímulos à inovação. As pressões da sociedade organizada exigindo mudanças, redimensionamento e o fortalecimento do INPI para estimular a incorporação tecnológica na produção e a inovação - que se apresenta como o principal foco da Política Industrial - dão respaldo parcial a esta afirmação.

Ficou razoavelmente evidenciado que na busca de fomentar a C,T\&I no país, tanto a Lei de Inovação como as Diretrizes da Política Industrial e Tecnológica, o Plano de Ação de Ciência, Tecnologia e Inovação para o Desenvolvimento Nacional - 2007/2010 e a Política de Desenvolvimento Produtivo fazem parte de um ciclo, que partiu da discussão focada nos recursos, atingiu os aspectos institucionais e que agora precisam ser implementados. Observa-se, após a regulamentação da Lei de Inovação que ainda existem aspectos que necessitam um maior detalhamento, de forma a preservar a identidade tanto das universidades quanto das indústrias e 
empresas, para que, de fato, ela possa vir a se tornar um instrumento relevante de fomento à política industrial e tecnológica do país.

É sabido em economia que o número de patentes tem estreita relação com a competitividade do produto e, por extensão, com a taxa de crescimento do PIB do país. Assim, aceito que o registro de patentes se apresenta como um indicador da inovação e o número de patentes conferidas a determinado país reflete seu dinamismo tecnológico, verifica-se que os nove anos de vigência dos fundos setoriais, cinco da Lei da Inovação e mais três Lei do Bem anda não melhorou o desempenho tecnológico do Brasil em relação aos demais países em desenvolvimento.

Cabe ao Estado orientar, apoiar e estimular o processo de inovação tecnológica no país, sem desconsiderar que a transformação da indústria é de responsabilidade da própria indústria. A Lei de Inovação é um instrumento legal importante nesse contexto, que não pode ser vista, porém, como decisiva para fomentar a construção de um modelo de desenvolvimento tecnológico autônomo no Brasil. As mudanças ocorridas no campo institucional nos últimos oito anos ainda não estão produzindo resultados consistentes. Dessa forma, fica evidenciado que é necessário ir mais além da estruturação de um arcabouço institucional no campo da C,T\&I. Para superar as dificuldades aqui assinaladas e atingir os seus objetivos é essencial que ocorra uma efetiva interação das ações governamentais com o segmento privado, comunidade científica e tecnológica e trabalhadores.

Uma política industrial e tecnológica adequada, com base na literatura, deve se valer de políticas setoriais, políticas de compras do setor público, financiamentos e incentivos à produção, ao investimento e à inovação na economia real. Assim, é essencial vincular a política industrial ao setor externo, visto que o país necessita de tornar-se competitivo nas exportações. Isso nos permite sustentar que a implementação da nova política industrial e tecnológica ainda não está apta a cumprir adequadamente o papel para a qual foi proposta, especialmente em relação às políticas de estímulos à inovação e ao patenteamento.

É inegável que a dinamização do uso da propriedade intelectual necessita de suporte e estímulos institucionais. As políticas públicas de proteção à propriedade intelectual se fazem necessário, especialmente para os universidade e centros de pesquisas e para as indústrias, visto que nesse campo ocorre grande parte da criação e inovação tecnológica e cultural, a partir das teses, conceitos e teorias potencialmente geradoras de tecnologias inovadoras. A geração de estímulos e de parcerias para fomentar as ações conjuntas entre as universidades e os centros de pesquisa e o segmento industrial é essencial para facilitar o intercâmbio de informações específicas para agilizar os processos de pedidos de patente e a definição dos parâmetros de comercialização e transferência de tecnologia.

Argumentamos, por fim, que o desconhecimento sobre registro de marcas e patentes está afetando as empresas brasileiras, gerando riscos desnecessários nas exportações de seus produtos. 
Diante das deficiências e fragilidade do sistema de gestão de políticas de proteção à propriedade intelectual, argumentamos que é essencial que o país continue se modernizando nessa área, em particular no segmento de registro de marcas e patentes. Torna-se essencial que o país intensifique a utilização da proteção à propriedade intelectual como um instrumento de suporte ao processo de desenvolvimento sócio-econômico. Essas mudanças devem ser implementadas, necessariamente, por meio da gestão de políticas públicas consistentes.

\begin{abstract}
The aim of this paper is to analyze the weaknesses and prospects for managing the system of intellectual property protection in Brazil, in particular the registration of patents and trademarks. The analysis was based on the country's institutional framework in the area object of study: Law of Industrial Property of 1996, the guidelines of the Industrial, Technological and Foreign Trade, 2004, the Technology Innovation Act of 2005, Law Well, in 2005, the Productive Development Policy, 2008, the Plan of Action for Science, Technology and Innovation for National Development 2007-2010. Examination of the improvements that were introduced in the institutional framework in Brazil in recent years and the improvements that resulted in the management of public policies to protect intellectual property showed that there are still serious difficulties in deployment and management policies, in particular in the segment register trademarks and patents.
\end{abstract}

Key-words: industrial policy and technology; intellectual property; trademarks and patents; economic development; Brazil.

\title{
Referências
}

ÁVILA, J. O INPI e a propriedade intelectual no brasil: resultados e metas. In. CONGRESSO BRASILEIRO DE INOVAÇÃO NA INDÚSTRIA, 2, 2007, São Paulo. Anais eletrônicos... São Paulo: CNI, 2007. Disponível em: http://www.cni.org.br.

. Open innovation e o sistema naconal de inovação. In. OPEN INNOVATION SEMINAR, 2003, São Paulo. Anais... São Paulo: FGV, 2008.

BRASIL. Ministério do desenvolvimento, indústria e comércio exterior. Diretrizes de política industrial e tecnológica e de comércio exterior. Brasília: MDIC, 2004.

Ministério do desenvolvimento, indústria e comércio exterior. Política de desenvolvimento produtivo. Brasília: MDIC, 2008. Disponível em: <http:// www.mdic.gov.br>. Acesso em: 01 jun. 2009.

. Ministério da ciência e tecnologia. Indicadores sobre ciência e tecnologia no brasil. 2004. Disponível em:

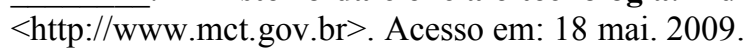

. Ministério da ciência e tecnologia. Plano de ação de ciência, tecnologia e inovação para o desenvolvimento nacional. Brasília: MCT. 2007-2010.

BARBIERI, J. C. Utilização de patentes no brasil. Relatório de Pesquisa, nº. 43. São Paulo: EAESP - Fundação Getúlio Vargas, 1998.

CHAVANNE, A.; BURST, Jean-Jacques. Droit de la proprieté industrielle. Paris: Précis-dalloz, 1993.

CONFEDERAÇÃo NACIONAL DA INDÚSTRIA. Políticas Públicas de Inovação no Brasil: a agenda da indústria. CNI: São Paulo, 2005a.

. Gestão da propriedade intelectual. In. CONGRESSO BRASILEIRO DE INOVAÇÃO NA INDÚSTRIA, 1, 2005b. Anais... São Paulo: CNI, 2005b. 
COUTINHO, L.; FERRAZ, J. C. (Coordenadores). Estudo da competitividade da indústria brasileira. Campinas/São Paulo: Papirus/Editora da Universidade Estadual de Campinas, 1994.

DAHLMAN, Carl J. New dimensions of innovation and competitiveness policies: international experiences. In. Congresso Brasileiro de Inovação na Indústria, 2, 2007. Anais eletrônicos... São Paulo: CNI, 2007. Disponível em: $<$ http://www.cni.org.br>.

ERBER, F. S. A propriedade industrial como instrumento de competição entre empresas e objeto de política estatal: uma introdução. Pesquisa e planejamento econômico, v.12, nº. 3, IPEA, Rio de Janeiro, 1982.

FERREIRA, C. E. M., et al. Estudo da viabilidade técnica e econômica da inventiva nacional: projeto inventiva. Relatório final. Brasília: MICT/STI, INPI, SEBRAE E FIESP/CIESP, 1998.

FREEMAN, C.; PEREZ, C. Structural crises of adjustment: business cycles and investment behavior. In. DOSI, G et al. (eds.). Technical change and economic theory. London: Pinter, 1988.

FRISCHTAK, C. The protection of intellectual property rights and industrial technology development in Brazil. Industry series papers, $\mathrm{n}^{\circ}$. 13, Industry and energy department, Washington-DC: World Bank, 1989.

FRITSCH, W.; FRANCO, G. Foreign direct investment in Brazil. OCDE, Paris, 1991.

GUIMARÃES, E. A. Políticas de inovação: financiamento e incentivos. Brasília: IPEA, Texto para Discussão 1212 , 2006, p. 1-69.

JAGUARIBE, R. Política industrial e os desafios para a competitividade. In. SEMINÁRIO INTERNACIONAL CELSO FURTADO, 2006, São Paulo. Anais... São Paulo, 2006.

KIM, L. Imitation to innovation: the dynamics of Korea's technological learning. Boston: Harvard Business Scholl Press, 1997.

Tecnologia, aprendizado e inovação: as experiências das economias de industrialização recente. São Paulo: Editora Unicamp, 2005.

KURZ, R. 0 Colapso da modernização. Rio de Janeiro: Ed. Paz e Terra, 1992.

MATIAS-PEREIRA, J.; KRUGLIANSKAS, I. Gestão de políticas de proteção à propriedade intelectual no brasil. In. Simpósio de Gestão de Inovação Tecnológica, 23, 2004, Curitiba, pp. 1-15. Anais... Curitiba: NPTG/ANPAD, 2004.

A lei de inovação como instrumento de suporte à política industrial e tecnológica do Brasil. Revista de Administração de Empresas (RAE-eletrônica), abril-julho 2005, pp. 1-18. Disponível em: <http://www.rae.com.br>. Acesso em: 25 jun. 2009.

MATIAS-PEREIRA, J. et al. Brazilian new patterns of industrial, technological and foreign trade policy. Journal of Technology Management Innovation, 1 (3): 17-28, 2006.

MATIAS-PEREIRA, J. Manual de Gestão Pública Contemporânea. 2. ed. São Paulo: Atlas, 2009.

MARCOVITCH, J. Administração em ciência e tecnologia. São Paulo: Ed. Edgard Blücher, 1983.

MENDONÇA, M. Políticas Públicas, de Inovação no Brasil: a agenda da indústria. Revista parcerias estratégicas, N. 21, Brasília - DF, dezembro, p. 05-32, 2005.

ORGANIZAÇÃO PARA A COOPERAÇÃO ECONÔMICA E O DESENVOLVIMENTO (OCDE). Main science and technology indicators, $n^{\circ}$. 2, Paris: OCDE, 1997.

OECD. Technology and industrial performance. Paris: OCDE, 1996.

Managing national innovation systems. Paris: OCDE, 1999.

Brazil - economic survey. Paris: OCDE, 2001.

Science, technology and industry scoreboard. Paris: OCDE, 2003. 
PAVITT, K. Sectorial patterns of technical change. Research policy, n. 13, p. 343-373, 1984.

cross ${ }^{\text {ref }}$

What makes basic research economically useful? Research policy, v. 20, n. 2, pp. 109-119, 1991.

cross $^{\text {ref }}$

cross ${ }^{\text {ref }}$

The social shape of the national science base. Research policy, v. 27, n. 8, pp. 793-805, 1998.

PATEL, P.; PAVITT, K. National innovation systems: why they are important, and how they might be measured and compared. Economics of innovation and new technology, v. 3, n. 1, p. 77-95, 1994a.

cross ${ }^{\text {ref }}$

. Uneven (and divergent) technological accumulation among advanced countries: evidence and a framework of explanation. Industrial and corporate change, v. 3, n. 3. 759-787, 1994b.

cross ${ }^{\text {ref }}$

Patterns of technological activity: their measurement and interpretation. In. STONEMAN, P. (ed.) Handbook of the economics of innovation and technological change. Oxford: Blackwell, 1995.

PENROSE, E. The Economics of international patent system. Baltimore: The Johns Hopkins Press, 1951.

ROMER, P. M. Increasing returns and long-run growth. Journal of political economy, v.94, n.5, p.1002-37, 1986.

cross ${ }^{\text {ref }}$

. Growth based on increasing returns due to specialization. American economic review, 77: 56-62, 1987.

. Endogenous Technological Change. Journal of political economy, 98 (5): 71-102, 1990.

cross ref

. Two strategies for economic development: using ideas and producing ideas. THE WORLD BANK ANNUAL CONFERENCE ON DEVELOPMENT ECONOMICS, 1992, Washington. Proceedings... Washington, D.C.: World Bank, 1993.

SCHUMPETER, J. A. A teoria do desenvolvimento econômico, São Paulo: Editora Abril, 1982.

SHERWOOD, R. M. Propriedade intelectual e desenvolvimento econômico. São Paulo: Edusp, 1992.

SOLOW, R. A contribution to the theory of economic growth. Quarterly journal of economics, v. 70, 1956.

crossef

cross ref

Technical change and the aggregate production function. Review of economics and statistics, v.39, 1957.

Growth theory: an exposition. Oxford University Press, New York e Oxford, 1988.

TORNATZKY, L. G.; FLEISCHER, M. The process of technological innovation. Lexington, MA: Lexington Books, 1990.

USPTO - United States Patents and Trademark Office. Annual report of the register of copyrights. 2005. Disponível em: <http://www.copyright.gov/reports/annual/2005/cover1.pdf $>$. Acesso em: 13 jun. 2009.

- United States Patent and Trademark Office. Performance and accountability report. 2007. Disponível

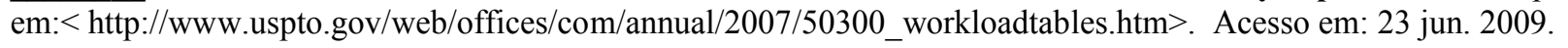

WARSH, D. Knowledge and the wealth of nations. New York: W. W. Norton, 2006. 


\section{Dados do autor:}

Nome completo: José Matias Pereira

Filiação institucional: Universidade de Brasília

Departamento: Programa de Pós-Graduação em Administração da Universidade de Brasília (PPGA/UnB)

Função ou cargo ocupado: Professor-pesquisador associado

Endereço para correspondência (bairro, cidade, estado, país e CEP): SHIS QI 26 Conjunto 5 Casa 22 - Lago Sul - Brasília - DF - 71670-050

Telefones para contato: 61-81524466

E-mail:matias@unb.br

Recebido para publicação em: 06/04/2010

Aceito para publicação em: 20/09/2010 